\title{
COST MANAGEMENT AND CORPORATE PERFORMANCE MEASUREMENT IN SUSTAINABLE SUPPLY CHAIN
}

DOI: 10.17261/Pressacademia.2020.1340

PAP- V.12-2020(4)-p.16-20

\section{Deniz Ozbay}

Maltepe University, Faculty of Business and Management Sciences, İstanbul, Turkey denizozbay@maltepe.edu.tr, ORCID: 0000-0003-4643-7577

\section{To cite this document}

Ozbay, D., (2020). Cost management and corporate performance measurement in sustainable supply chain. PressAcademia Procedia (PAP), V.12, p.16-20.

Permanent link to this document: $\mathrm{http} / / /$ doi.org/10.17261/Pressacademia.2020.1340

Copyright: Published by PressAcademia and limited licensed re-use rights only.

\section{ABSTRACT}

Purpose- The purpose of the study is to propose a model to measure the success performance of businesses which have adopted Sustainable Supply Chain Management (SSCM) practices.

Methodology- A literature review was carried out based on some concepts such as SSCM, sustainability and business performance, social performance and financial performance, and sustainable cost management.

Findings- When the literature is examined, it is seen that SSCM is considered to be more of a business's practices for reducing environmental impact. In addition, In many studies which examine the relationship between SSCM and firm performance, cost savings are often used as financial performance indicators. But, the fact that sustainability-based practices will generate many different cost factors has been overlooked in many studies. On the other hand, It is seen that the number of studies on cost management and performance measurement in SSCM practices is quite limited.

Conclusion- Considering the effects of sustainability-based practices in measuring business performance is important for the definition of long-term success indicators and accurate performance measurements.

Keywords: Sustainable supply chain management, sustainabiliy performance, corporate perfromance, cost management, sustainable balanced scorecard.

JEL Codes: M14, M40, L25

\section{SÜRDÜRÜLEBILIR TEDARIK ZINCIRINDE MALIYET YÖNETIMI VE KURUMSAL PERFORMANS ÖLÇÜMÜ}

\section{ÖZET}

Amaç- Çalışmanın amacı Sürdürülebilir Tedarik Zinciri Yönetimi (STZY) uygulamalarını benimsemiş işletmelerde, başarı performansını ölçmeye yönelik bir model önerisi sunmaktır.

Yöntem- STZY, sürdürülebilirlik ve işletme performansı, sosyal performans ve finansal performans, sürdürülebilir maliyet yönetimi gibi kavramlar baz alınarak literatür taraması yapılmıştır.

Bulgular- Literatür incelendiğinde, STZY'nin, genel olarak, işletmenin çevresel etkiyi azaltmaya yönelik uygulamaları olarak değerlendirildiği görülmektedir. Bunun yanında, STZY ve işletme performansı arasındaki ilişkinin incelendiği birçok çalışmada, finansal performans göstergesi olarak maliyet tasarruflarının kullanıldığı görülmektedir. Ancak, sürdürülebilirlik temelli uygulamaların çok sayıda farklı maliyet unsurunu da ortaya çıkaracak olması birçok çalışmada göz ardı edilmiştir. STZY uygulamalarında maliyet yönetimini ve performans ölçümlerini konu alan çalışmalarının sayısının ise oldukça sınırlı kaldığı görülmektedir.

Sonuç- İşletme performansını ölçmede sürdürülebilirlik temelli uygulamaların etkilerini de dikkate almak, uzun vadeli başarı göstergelerinin tanımlanması ve performans ölçümlerinin doğru yapılması adına önem taşımaktadır.

Anahtar Kelimeler: Sürdürülebilir tedarik zinciri yönetimi, sürdürülebilirlik performansı, kurumsal performans, maliyet yönetimi, sürdürülebilir balanced scorecard.

JEL Kodları: M14, M40, L25 


\section{GiRiş}

Günümüzde çevresel sürdürülebilirlik, atık yönetimi, kaynakların etkin kullanımı gibi konular, gelişmiş ya da gelişmekte olan tüm ekonomilerin ortak problemi haline gelmiştir. Kaynakların sınırlı oluşu ve etkin bir şekilde yönetilmesi gerekliliği toplumsal baskıyı artırmakta, işletmeler de bu baskı karşısında duyarsız kalamamaktadır. Çevresel etkileri ve kaynak tüketimleri dikkate alındığında, sürdürülebilirlik stratejisi belirlemek adına imalat işletmelerine de önemli sorumluluklar düşmektedir (Esfahbodi, et. al. 2016: 352). Çalışmanın amacı "Sürdürülebilir Tedarik Zinciri Yönetimi (STZY)" uygulamalarını benimsemiş işletmelerde, uygun maliyet yönetim tekniklerini belirlemek ve kurumsal performansı ölçmeye yönelik bir model önerisi sunmaktır. Bu bağlamda çalışma üç alt başıktan oluşmaktadır. Illk olarak, STZY dinamiklerinin belirlenmesi amaçlanmaktadır. İkinci olarak, STZY'nin uygulama aşamalarında ortaya çıkan maliyetlerin belirlenmesi ve maliyet yönetimi için uygun tekniklerinin tartışılması hedeflenmektedir. Son olarak, çalışma kapsamında, STZY bileşenlerini de dikkate alarak işletme performansını ölçmeyi amaçlayan, "Sürdürülebilir Balanced Scorecard" modeli önerilmektedir.

\section{SÜRDÜRÜLEBiLIR TEDARIK ZINCIRI YÖNETIMI}

Lee ve Billington’a (1992: 62) göre tedarik zinciri, hammaddelerin temin edilmesi, bunların yarı mamul ve nihai mamule dönüştürülmesi ve bir dağııım kanalı vasıtasıyla ürünlerin müşterilere ulaştırıımasını sağlayan bir ağdır. Tedarik zinciri içinde tedarikçiden nihai müşteriye kadar birbirine bağımlı bir süreçten bahsedilmektedir. Bu sürecin yönetilmesi Tedarik Zinciri Yönetimi (TZY) kavramıyla ifade edilmektedir. TZY, üreticilerin, depoların ve müşterilerin verimli bir şekilde entegre edilmesi için kullanılan ve ürünlerin doğru miktarda, doğru yere ve doğru zamanda üretilip dağıııımasını en az maliyetle gerçekleştiren yaklaşımların tümüdür (Khan vd., 2010: 404). Sürdürülebilir tedarik zinciri ise tedarik zincirinin her sürecine, sürdürülebilirlik bakış açısı ve uygulamalarının entegre edildiği bir sistemi ifade etmektedir. Dolayısıyla, önce sürdürülebilirliği kısaca tanımlamakta fayda bulunmaktadır. Sürdürülebilirlik; toplumsal, sosyal, kültürel, bilimsel, doğal vb. tüm kaynakların ihtiyatlı kullanımını sağlayan ve buna saygı gösterme yönünde sosyal bir bakış yaratan katılımcı bir süreçtir (Gladwin, vd. (1995:877). Bu tanımdan hareketle, Sürdürülebilir tedarik zinciri yönetimi (STZY); uzun vadeli bir ekonomik performans ile sosyal, çevresel ve ekonomik hedeflerinin başarımı için, tedarik zincirlerinde yer alan tüm yapılardaki iş süreçlerin sistematik koordinasyunu ve şeffaf entegrasyonu olarak tanımlanmaktadır (Carter and Rogers, 2008:368). Esfahbodi, vd. (2016: 353), STZY'ni dört süreçte ele almaktadır. Bunlar; sürdürülebilir tedarik, sürdürülebilir üretim, sürdürülebilir dağıtım ve tersine lojistik faaliyetleridir. Bu çalışma kapsamında STZY, Esfahbodi, vd. (2016) ile benzer şekilde, bu dört süreç altında değerlendirilecektir.

\section{SÜRDÜRÜLEBiLIR TEDARIK ZINCIRINDE MALIYET YÖNETIMI}

STZY ve finansal performans arasındaki ilişkiyi inceleyen çoğu çalışmada, STYZ ile azalan maliyetlerin finansal performansı arttırdığı ileri sürülmekle birlikte, STZY'nin farklı bir çok maliyet unsurunu da ortaya çıkardığı, bu nedenle maliyetleri artırdığı ve dolayısıyla finansal performansı olumsuz olarak etkilediği görüşünü savunan araştırmacılar da mevcuttur (Ortas, vd., 2014). Günümüzde işletmeler bir yandan yüksek bir STZY performansına intiyaç duyarken, diğer yandan da maliyet maksimizasyonu sağlama ihtiyacı duymaktadır (Jakhar, 2015). Bu nedenle STZY' de maliyetleri en aza indirecek tekniklerin kullanılması gerekmektedir. Öte yandan, STZY ya da yeşil tedarik zinciri yönetimini konu alan birçok çalışmada, maliyetlendirme ve performans değerlendirmesinin sistematik ve kapsamlı bir şekilde entegre edilmediği görülmektedir. Maliyet ve fayda ölçülerinin değer zincirine entegre edilmesi, performansı daha net ortaya çıkacaktır (Tsai \& Hung, 2009). Dolayısıyla, STZY'de maliyet - fayda analizlerinin yapılabilmesi için ilk olarak süreç içinde ortaya çıkacak maliyetlerin ve maliyet tasarruflarının belirlenmesi gerekmektedir. Tablo 1, STZY'de ortaya çıkması beklenen maliyetler ile zaman içinde azalması öngörülen maliyetler özetlemektedir.

Tablo 1: Sürdürülebilir Tedarik Zinciri Maliyetleri ve Maliyet Tasarrufları

\begin{tabular}{|l|l|}
\hline STZY MALiYETLERi & KAYNAK \\
\hline 1. Sürdürülebilir Tedarik Maliyetleri & \\
\hline Tedarikçi seçim süreci / ölçme ve değerlendirme & Lin, vd. 2001; Ortas, vd. 2014; Wang \& Dai, 2018 \\
\hline Gecikme / iptal & Ortas, vd. 2014 \\
\hline Tedarikçi denetimleri & Ortas, vd. 2014; Zhu, vd. 2005 \\
\hline 2. Sürdürülebilir Üretim Maliyetleri & \\
\hline Sürdürülebilir tasarım & Zhu, vd. 2005 \\
\hline Sürdürülebilir ilk madde ve malzeme & Seuring, 2001; Zhu, vd. 2005 \\
\hline İ̧gücü eğitimi & Jakhar, 2015; Zhu, vd. 2005; Wang \& Dai, 2018 \\
\hline Sürdürülebilir ücret uygulaması & Wang \& Dai, 2018 \\
\hline Operasyonel maliyetler & Pettersson \& Segerstedt, 2013; Zhu, vd. 2005 \\
\hline Kalite denetimleri & \\
\hline Sürdürülebilir ambalajlama & Zhu, vd. 2005; Wang \& Dai, 2018 \\
\hline Sürdürülebilir depolama & Lin, vd. 2001 \\
\hline 3. Sürdürülebilir Dağııım Maliyetleri & \\
\hline Ulaşım/transfer maliyetleri & Lin, vd. 2001; Seuring, 2001 \\
\hline Dağı̈ım kanallarının denetimi & \\
\hline Müşteri ilişkileri yönetimi & \\
\hline 4. Tersine Lojistik Maliyetleri & Esfahbodi, vd. 2016 \\
\hline 5. Sürdürülebilir Yapı Maliyetleri & \\
\hline Sertifikasyon maliyetleri & Ortas, vd. 2014; Wang \& Dai, 2018 \\
\hline Arıtma, filtreleme, geri dönüşüm sistemi yatırım maliyetleri & Zhu, vd. 2005 \\
\hline Sürdürülebilir ar-ge sistemi & \\
\hline
\end{tabular}




\begin{tabular}{|l|l|}
\hline $\begin{array}{l}\text { Sürdürülebilirlik temelli teknoloji yatırımları kurulum ve iyileştirme } \\
\text { maliyetleri (MIS, ERP) }\end{array}$ & Tsai \& Hung, 2009 \\
\hline Sosyal sorumluluk temelli yatırımlar & \\
\hline STZ MALiYET TASARRUFLARI & KAYNAK \\
\hline Enerji kullanımında azalma & Jakhar, 2015; Prasad, vd. 2020; Zhu, vd. 2005; Wang \& Dai, 2018 \\
\hline Su kullanımında azalma & Zhu, vd. 2005 \\
\hline Malzeme israfında azalma & Zhu, vd. 2005 \\
\hline Hatalı ürün oranında azalma & Jakhar, 2015 \\
\hline Depolama maliyetlerinde azalma & Jakhar, 2015; Zailani, vd. 2012; Seuring, 2001; Zhu, vd. 2005 \\
\hline Atık/imha maliyetlerinde azalma & Jakhar, 2015; Zailani, vd. 2012; Tsai \& Hung, 2009; Zhu, vd. 2005 \\
\hline Kaynakların verimli kullanımıyla operasyonel maliyetlerin azalması & Zailani, vd. 2012 \\
\hline Kapasite kullanım maliyetlerinde azalma & Seuring, 2001 \\
\hline Sevkiyat maliyetlerinde azalma & Seuring, 2001 \\
\hline
\end{tabular}

La Londe ve Pohlen (1996), tedarik zinciri maliyetlerinin açıkça ölçülmediğine işaret eden ilk kişilerdir (Hoffman \& Boshshard, 2017:718). Geleneksel muhasebe sistemleri, ürünlerin gerçek maliyetlerini belirlemek adına yetersiz kalmaktadır (Hoffman \& Boshshard, 2017:718). Bu nedenle, STZY için stratejik maliyet yönetim tekniklerinin kullanılması daha uygun olacaktır. Literatür incelendiğinde, STZY'de maliyet yönetimi konusunu ele alan çalışmaların oldukça kısıtlı olduğu görülmektedir. Tedarik zincirinde maliyet yönetimi konulu çalışmalarda ise en çok yer verilen maliyet yönetimi yaklaşımı “Faaliyet Tabanlı Maliyetleme - FTM” olarak karşımıza çıkmaktadır (Dekker \& Van Goor, 2000; Lin, vd., 2001; Seuring, 2001; Tsai \& Hung, 2009; Askarany, vd., 2010; Hoffman \& Boshshard, 2017). FTM, özellikle tedarik zincirinin sürdürülebilir üretim aşamasında, katma değer yaratan ve yaratmayan faaliyetleri birbirinden ayırarak, gereksiz maliyetlerin ortadan kaldırılması için önemli bilgiler sunmaktadır. Yine üretim aşamasında, "Tam Zamanında Maliyetleme- TZM"nin önemine vurgu yapan çalışmalar da bulunmaktadır. TZM, stokların en aza indirilmesi için üretim faaliyetinin büyük bir hassasiyetle hesaplanması ve tasarlanması gerektiği fikrine dayanmaktadır. Stoklarda minimum düzeyde hammadde, malzeme ve mamullerin bulundurulması, üretim hacminden bağımsız olarak genel maliyetleri düşürmektedir (Abusef \& Rathi, 2013: 100). Sürdürülebilir tedarik zincirini bir değer zinciri olarak ele alıp, "Hedef Maliyetleme”, "Toplam Kalite Yönetimi", "Yalın Üretim", ve "Mamul Yaşam Süresince Maliyetleme” gibi tekniklerin de ayrı ayrı kullanımı mümkünken, tüm bu teknikleri sürece entegre etmek de mümkündür. Bazı araştırmacılar, ürün maliyetlerinin yüzde 80'inin tasarım aşamasında gerçekleştirildiğini savunmaktadır (Abusef \& Rathi, 2013: 97). Tasarım aşamasında malzeme seçimi, üretim yöntemi, üretme veya satın alma ile ilgili önemli kararlar verilmekte olup, tüm bu kararlar, bir ürünün maliyetleri üzerinde büyük bir etkiye sahiptir. Pazarlama ve dağıtım verimlilikleri vasıtasıyla elde edilen maliyet kazançları, daha iyi ürün planlama ve tasarım yoluyla elde edilen maliyet kazançlarından önemli ölçüde daha küçüktür (Abusef \& Rathi, 2013: 97). Dolayısıyla hedef maliyetlemenin en etkin kullanılabileceği aşamalardan biri tasarım aşamasıdır. Ancak tüm bu yöntemlerin başarılı olabilmesi için sistemin tedarikçilerle entegre bir şekilde çalışması gerekmektedir. Başka bir ifadeyle, sürdürülebilir tedarik aşamasının da aynı yaklaşımlar çerçevesinde şekillenmiş olması gerekir. Öte yandan TKY, sadece üretim süreçlerinde kaliteye odaklanmamaktadır. Satış sonrası, müşteri ilişkileri dahil, tüm sürecin iyileştirilmesi için gerekli işlemlerin tamamını kapsamaktadır (Basık, 2012). Dolayısıyla, sürdürülebilir dağıtım ve tersine lojistik faaliyetlerin verimliliği artırmak için, TKY uygun bir yaklaşım olmaktadır. Bu yöntemler aslında birer felsefe olarak görülmekte olup, amaç maliyet kontrolü değil, maliyetlerin düşürülmesidir (Basık, 2012). İşletmelerin; kendi iç işleyişlerine, sektörlerine ve çalışma koşullarına bağlı olarak, sürdürülebilir tedarik zincirinin her aşamasında uygun maliyet yönetimi tekniklerini kullanmaları, sürdürülebilirlik yönetimini çok da verimli bir şekilde gerçekleştirmeleri adına önem arz etmektedir.

\section{STZY'DE BAŞARI PERFORMANSININ ÖLÇÜLMESI}

"Balanced Scorecard (BSC)" ilk olarak 1992 yılında Robert Kaplan ve David Norton tarafından sunulmuştur. BSC, işletmenin finansal performansı yanında finansal olmayan performansını da dikkate alarak başarıyı ölçmeyi hedeflemektedir. Başarıdan kasıt, işletmenin hedeflediği stratejik amaçlara ne kadar yaklaştığı ya da ne kadarını başardığıdır (Basık, 2012:189-190). BSC; finansal boyut, müşteriler boyutu, iç süreçler boyutu ve öğrenme ve gelişme boyutu olmak üzere , 4 boyuttan oluşmakta olup, her bir boyut altında belirlenen amaçlar, ölçüm yöntemleri, nihai hedefler ve bu konudaki girişimler baz alınarak performans değerlendirilmektedir. BSC, en çok tercih edilen performans değerlendirme araçlarından biri olmasına rağmen, birçok araştırmacı tarafından sosyal sorumluluk ya da sürdürülebilirlik performans göstergelerini kapsamamış olması nedeniyle eleştirilmektedir (Epstein \& Wisner, 2001; Figge, vd., 2002; Higgins \& Currie, 2004; Van der Woerd \& Van den Brink, 2004). Sürdürülebilirliğin ekonomik, sosyal ve çeveresel boyutu birçok disiplin altında incelenmekte ve literatürde geniş yer tutmaktadır. Bazı araştırmacılar sürdürülebilirlik uygulamalarını çevresel ve sosyal hassasiyetler boyutunda değerlendirirken, bazı çalışmalarda, özellikle ekonomik nedenler ön plana çıkmaktadır. İster çevresel, ister sosyal, isterse de ekonomik nedenlerle olsun, günümüzde, küresel piyasalarda aktif rol oynamak isteyen işletmelerin, sürdürülebilirlik uygulamalarından uzak kalarak varlığını devam ettirme şansları oldukça düşük görünmektedir. Bu nedenle sürdürülebilirlik uygulamalarının, işletme performansı içinde değerlendirilmesi gerektiği yönündeki görüşler yaygınlık kazanmaktadır. Litertürde yer alan görüşler ve model önerileri çerçevesinde, Tablo 2'de iş̧letme performansı ölçmede sürdürülebilirlik yaklaşımlarını da dikkate alan "Sürdürülebilir BSC" modeline yer verilmiştir.

Tablo 2: Sürdürülebilir BSC Modeli

\begin{tabular}{|c|c|}
\hline 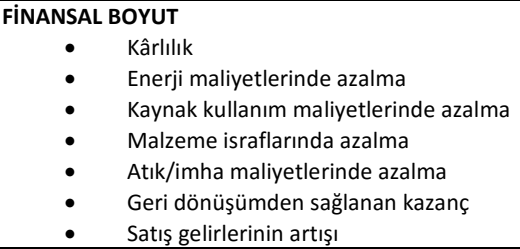 & 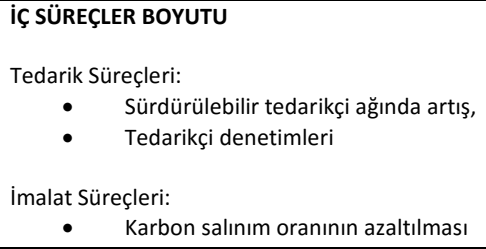 \\
\hline
\end{tabular}




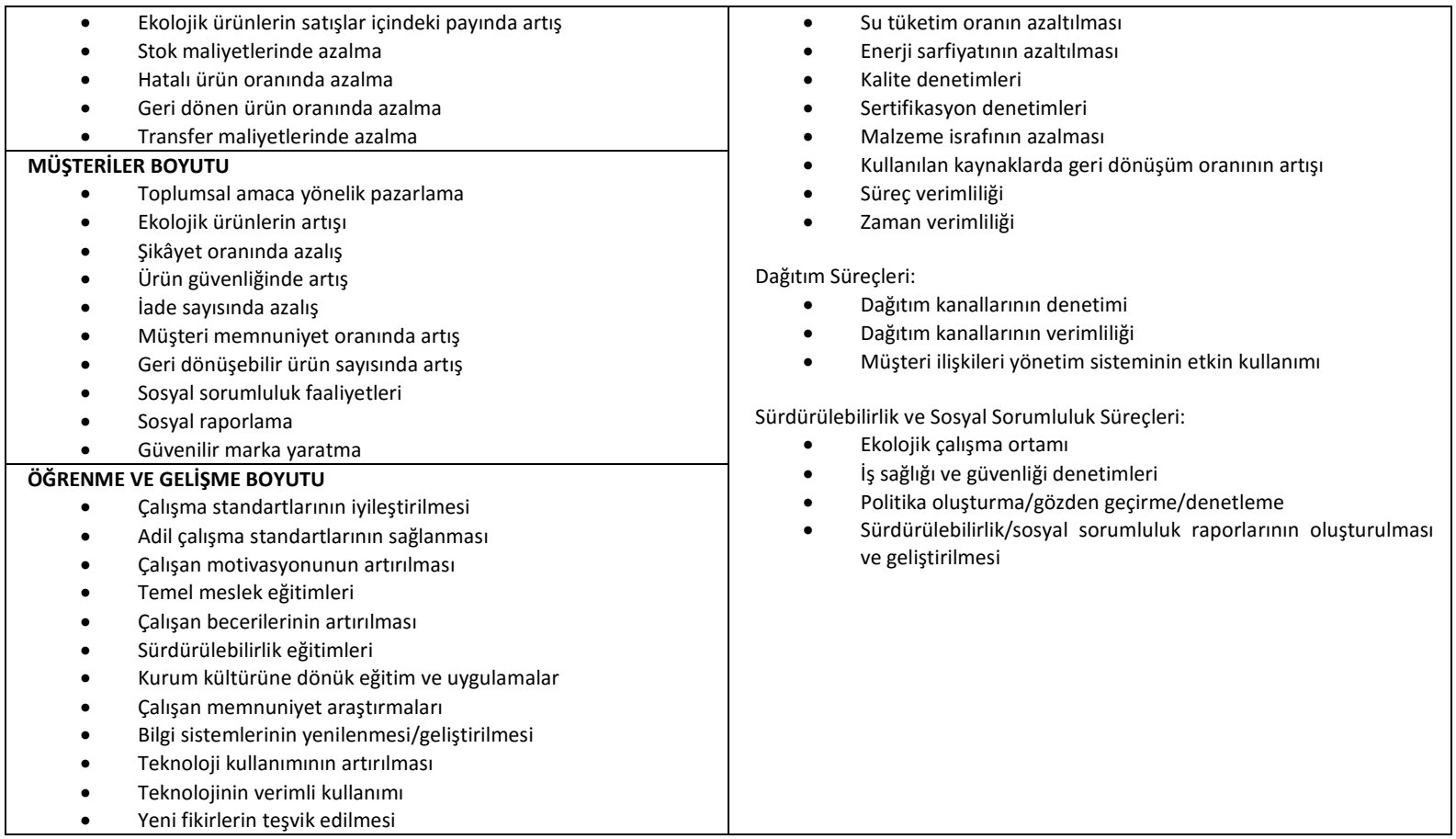

\section{SONUÇ}

Kurumsal sürdürülebilirlik, günümüzün en çok ilgi gören araştırma konularından biridir. Bu popülerliğin nedeni günümüz rekabetçi iş dünyasında sadece kısa vadeli finansal başarı odaklı olan işletmelerin varlığını sürdüremeyecek olmasıdır. Bununla birlikte, işletme performansını kısa vadeli finansal performansa indirgemek, paydaş beklentilerini dikkate alan günümüz iş dünyası dinamikleriyle bağdaşmamaktadır. STZY'de başarılı bir performans için, süreç içindeki maliyetlerin tespiti ve staratejik amaçlar doğrultusunda yönetimi önem arz etmektedir. İşletme performansını ölçmede sürdürülebilirlik temelli uygulamaların etkilerini de dikkate alan sürüdürülebilir BSC kullanımı, uzun vadeli başarı göstergelerinin tanımlanması ve performans ölçümlerinin doğru yapılması adına önem taşımaktadır.

\section{KAYNAKLAR}

Abusf, E. O., Rathi, N.S. (2013). Target Costing and It's in Reducing the Cost Comparison at Industrial Companies. International Journal of Management, 4(4): 94-102.

Askarany, D., Yazdifar, H.,Askary, D. (2010). Supply chain management, activity-based costing and organisational factors, International Journal of Production Economics, 127(2): 238-248.

Basık, F.O. (2012). Rekabet Stratejisinde Maliyet Yönetimi. İstanbul, Türkmen Kitabevi.

Carter, C. R., Rogers, D. S. (2008). A Framework of Sustainable Supply Chain Management: Moving Toward New Theory. International Journal of Physical Distribution and Logistics Management, 38(5): 360-387.

Dekker, H.,C., Van Goor, A.R. (2000). Supply Chain Management and Management Accounting: A Case Study of Activity-Based Costing. International Journal of Logistics, 3(1): 41-52.

Epstein, M.J., Wisner, P.S. (2001). Using a Balanced Scorecard to Implement Sustainability. Environmental Quality Management, $11(2):$ 1-10.

Esfahbodi, A., Zhang, Y., Watson, G. (2016). Sustainable supply chain management in emerging economies: Trade-offs between environmental and cost performance. International Journal of Production Economics, 181: 350-366.

Figge, F., Hahn, T., Schaltegger, S., Wagner, M. (2002). The sustainability balanced scorecard. Linking sustainability management to business strategy. Business Strategy and the Environment, 11(5): 269-284.

Gladwin, T., Kennelly, J., Krause, S.T. (1995). Shifting Paradigms for Sustainable Development: Implications for Management Theory and Research. Academy of Management Review, 20(4): 874-907.

Higgins, J., Currie, D. (2004). It's Time to Rebalance the Scorecard. Business and Society Review, 109: 279-309.

Hoffman, E., Boshshard, J. (2017). Supply chain management and activity-based costing current status and directions for the future. International Journal of Physical Distribution \& Logistics Management, 47(8).712-735. 
Jakhar, S.K. (2015). Performance evaluation and a flow allocation decision model for a sustainable supply chain of an apparel industry. Journal of Cleaner Production, 87: 391-413.

Khan, M. Z., Al-Mushayt, O., Alam, J., Ahmad, J. (2010). Intelligent Supply Chain Management. Journal of Software Engineering and Applications, 3(4): 404-408.

Lee, H. L. ve Billington, C., (1992). Managing Supply Chain Inventory: Pitfalls and Opportunities. Sloan Management Review, 33(3): 65-73.

Lin, B., Collins, J., Su, R.K. (2001). Supply chain costing: an activity based perspective. International Journal of Physical and Logistics Management, 31(10): 702-713.

Ortas, E., Moneva, J.M., Alvaraz, I. (2014). Sustainable supply chain and company performance A global examination. Supply Chain Management: An International Journal, 19(3): 332-350.

Pettersson, A.I., Segerstedt, A. (2013). Measuring supply chain cost. International Journal of Production Economics, 143(2): 357-363.

Prasad, D.S., Pradhan, R.P., Gaurav, K., Sabat, A.K. (2020). Critical Success Factors of Sustainable Supply Chain Management and Organizational Performance: An Exploratory Study. Transportation Research Procedia, 48: 327-344.

Seuring, S.A. (2001). Green Supply Chain Costing: Joint Cost Management in the Polyester Linings Supply Chain. Greener Management International, 33: 71-80.

Tsai, W.H., Hung, S.J. (2009). A fuzzy goal programming approach for green supply chain optimisation under activity-based costing and performance evaluation with a value-chain structure. International Journal of Production Research, 47(18): 4991-5017.

Van der Woerd, F., Van den Brink, T. (2004). Feasibility of a Responsive Scorecard - a pilot study. Journal of Business Ethics, 55:173-187.

Wang, J., Dai, J. (2018). Sustainable supply chain management practices and performance. Industrial Management \& Data Systems, 118 (1): 2-21.

Zailani, S., Jeyaraman, K., Vengadasan, G., Promkumar, R. (2012). Sustainable supply chain management (SSCM) in Malaysia: A survey. International Journal of Production Economics, 140 (1): 330-340.

Zhu, Q., Sarkis, J., Geng, Y. (2005). Green supply chain management in China: pressures, practices and performance, International Journal of Operations \& Production Management, 25(5): 449-468. 